\title{
The effects of adapted physical exercise during rehabilitation in patients with traumatic brain injury
}

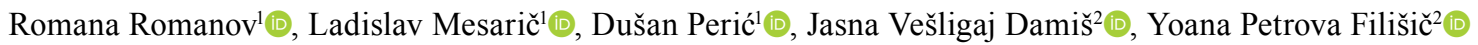 \\ ${ }^{1}$ Faculty of sport and tourism, Educons University, Novi Sad, Serbia \\ ${ }^{2}$ Rehabilitation Center "Naprej", Maribor, Slovenia
}

Received: March 03, 2020 Accepted: October 21, 2020 Published online: December 01, 2021

\begin{abstract}
Objectives: This study aims to investigate the effects of adapted physical exercise on the level of muscular ability and attention process in patients with traumatic brain injury (TBI).

Patients and methods: Between September 2018 and November 2018, a total of 25 male patients with TBI (mean age: $41.1 \pm 9.7$ years; range, 30 to 50 years) that occurred two years ago were included in this randomized-controlled study. The patients were divided into two groups as the experimental group $(n=13)$ and the control group $(n=12)$. The experimental group implemented a regular rehabilitation program and an additional program of adapted physical exercise. The control group implemented only a regular rehabilitation program (morning gymnastics and gymnastics for the brain). Motor and functional abilities were assessed by a Senior Fitness battery and Berg's balance scale. Attention process was assessed by a standardized $\mathrm{d} 2$ test.

Results: A significant improvement in physical abilities (strength, flexibility and balance) and attention process was observed in both groups $(\mathrm{p}<0.01)$. The improvement was greater in the experimental group $(\mathrm{p}<0.01)$.

Conclusion: Traumatic brain injury causes difficulties in the memory and executive functions of the body and impairs working ability. The short-term adapted physical exercise program can yield a positive change in working abilities of patients with TBI.

Keywords: Attention process, balance, flexibility, physical therapy, strength, traumatic brain injury.
\end{abstract}

Traumatic brain injury (TBI) is regarded as the largest medical and social problem in the developed countries, ${ }^{[1]}$ which is supported by the fact that in 2016, the incidence of TBI worldwide was 27.08 million new cases (Global Burden of Diseases, Injuries, and Risk Factors [GBD] 2016 Traumatic Brain Injury and Spinal Cord Injury Collaborators, 2019), and it is most commonly identified between the ages of 15 to 45 years. ${ }^{[2,3]}$ Depending on the degree of impairment, this injury causes difficulties in the memory and executive functions of the body. The constraints that occur affect the individual's autonomy, in all areas of life, most notably in terms of daily living activities. ${ }^{[3]}$ Several studies have shown that men are twice as likely to be exposed to TBIs compared to women; ${ }^{[2,4]}$ nevertheless, the sedentary lifestyle and poor physical form associated with health and work capacity are equally identified by injury in both sexes.

Traumatic brain injury can be categorized as mild, moderate, or severe, depending on the clinical presentation $^{[5,6]}$ Mild TBI is characterized by loss

Corresponding author: Romana Romanov, MD. Educons University, Faculty of sport and tourism, Radnička 30a, 21000, Novi Sad, Republic of Serbia. 
of consciousness for a few seconds or minutes ( $\max 30 \mathrm{~min}$ ), alteration of consciousness/mental state may last up to $24 \mathrm{~h}$ and post-traumatic amnesia which may last up to one day; moderate TBI is characterized by loss of consciousness that may last up to a few hours ( $>30 \mathrm{~min}$ and $<24 \mathrm{~h}$ ), and confusion may last up to weeks, and post-traumatic amnesia may last for one to seven days; severe TBI is characterized by loss of consciousness more than $24 \mathrm{~h}$, as well as alteration of consciousness/mental state, but post-traumatic amnesia may last more than seven days. ${ }^{[7]}$ The complications can last for months and can be permanent. These complications can be physical, cognitive, or behavioral. ${ }^{[7]}$

Traumatic brain injury is related to changes in brain function, or other evident pathology of the brain caused by an external force (mechanical injury). Post-TBI conditions are related to temporary or permanent consequences that can be identified in an individual physically (biologically), psychologically, and socially ${ }^{[3]}$ and, thus, affecting their working ability. Changes are most commonly manifested as a disorder of cognitive function, speech, language, reasoning, information processing, abstract thinking ability, but in most cases, a disorder of bodily function (locomotor function) occurs. The most common disorder of bodily function is movement disorder, which includes varying degrees of paresis or plegia, impaired movement coordination, and/or involuntary movements (ataxia) that interfere with natural movement. ${ }^{[4,8]}$

In individuals with TBI, reduced values of maximal aerobic capacity are identified. Compared to healthy sedentary persons, these values are 25 to $30 \%$ lower and can be increased by the use of adapted physical exercise that improves the cardiorespiratory capacity of a patient with TBI. ${ }^{[9]}$ The use of an aerobic exercise program has been shown to not only improve cardiovascular and endurance performance, but also influence cognitive function in patients with TBI, ${ }^{[10]}$ that is, the better functioning of the brain structures in which the processes of memory and learning take place has been observed.

Muscle ability (strength, endurance) is significantly correlated with coordination and balance. Poor balance and spasticity are the main causes of mobility restriction. They are related to insufficient production of muscle strength and identified in a patient after a TBI. ${ }^{[1,12]}$ Strength exercises increase muscle mass, provide better stability and coordination, and can further prevent falls. Strength exercises affect muscle trophism, body awareness and perception, as well as improvement of the nervous system function. ${ }^{[13-15]}$

Good physical work ability is also related to an individual's personal feeling of being in good health. Reduced work or physical ability in TBI patients is associated with mobility limitations, but also with poor emotional health. ${ }^{[16,17]}$ The use of physical activity (adapted exercise) in patients with TBI is the first prerequisite for maintaining health, well-being, and working ability ${ }^{[18]}$ In the present study, we aimed to investigate the effects of adapted physical exercise on the level of muscular ability and to assess the attention process as a significant factor in general physical work ability in patients with TBI.

\section{PATIENTS AND METHODS}

This randomized-controlled study was conducted at Faculty of Sport and Toursm (Serbia) Center for people with traumatic brain injury - "Naprej" from Maribor (Slovenia), between September 2018 and November 2018. A total of 25 male patients with TBI (mean age: $41.1 \pm 9.7$ years; range, 30 to 50 years) that occurred two years ago were included in the study. Before the start of the study, the sample was homogenized in relation to the type, severity and duration of trauma. Patients were carefully selected and the study included only those who voluntarily joined the study and all of them were categorized as moderate and severe TBI after injury, could move independently without support, having a rehabilitation process for two years, having the same occupational and behavioral therapy and having no other (acute and chronic) diseases. The similarity of the clinical picture and voluntariness influenced the sample size, giving it the characteristics of an intentional controlled sample.

The study sample was divided into two groups randomly by the lottery method. The first group (experimental) consisted of 13 patients and the second group (control group) consisted of 12 patients. Prior to treatment, the groups were statistically homogenized (group equality was determined by t-test). Before the study, all participants were informed about the content and the aim of the research, and a written informed consent was obtained. The study protocol was approved by the Center Naprej Maribor Ethics Committee (No: 007-1/2017). The study was conducted in accordance with the principles of the Declaration of Helsinki. 
In this study, an additional adaptive exercise program was used. The same motor, functional, and psychological tests were applied before and after the experiment. The treatment was implemented over a period of eight weeks by the experts of kinesiology and psychology.

All participants attended to a regular rehabilitation program, five days a week (Monday to Friday), including two basic activities:

- Morning exercise, which was implemented as a daily activity for $45 \mathrm{~min}$, with the aim of improving circulation (endurance exercises), empowering the body (strength exercises), and increasing the volume of movement and general flexibility of the body (stretching exercises);

- Brain gymnastics, which is a set of simple and easy movements that are performed to improve brain function, that is, activation of both hemispheres of the brain. ${ }^{[21]}$ Exercises include movements such as diagonal movements, head movements, balance exercises, breathing exercises (abdominal), drawing (laid eight, symmetrical drawing), and exercises to improve proprioception, ${ }^{[21,22]}$ that are performed twice a week, on every Tuesday and Thursday, for $45 \mathrm{~min}$ in each session.

The experimental program (training) involved the use of adapted physical exercise, which was administered twice a week for $90 \mathrm{~min}$. The adaptation was aimed at facilitating the execution of certain exercises. Progressive load was applied. Each training session began with the Nordic walking using Gymnastic ${ }^{\star}$ rods (elastic band/rubber is an integral part of the rod, NW Gym) for 30 to 40 min (depending on the week the program was implemented). The realization of the exercises, then, began with the help of the Gymnastic ${ }^{\circ}$ for 50 to $60 \mathrm{~min}$. Each training session included eight strength-enhancing exercises performed in two rounds (eight repetitions each), two body balance-enhancing exercises, and four general flexibility exercises that were performed in two rounds (15 repetitions each). During the eight-week program, progressive load was applied, the number of repetitions in the series increased, the break time between rounds was shortened, and the duration of aerobic activity increased.

\section{Assessment variables}

The respondents' work ability was identified based on variables that included motor and functional ability and assessment of attention process. Motor and functional ability were assessed with five variables, using a Senior Fitness battery tests ${ }^{[23,24]}$ and Berg's Balance Scale (BBS). ${ }^{[25]}$

The four variables assessed by the Senior Fitness battery were as follows: (i) lower extremity strength was measured by the Chair Stand Test (CST) lasts for $30 \mathrm{sec}$, and the result of the test was the number of repetitions; (ii) upper limb strength was measured by the Biceps Curl Test (BCT) lasts for $30 \mathrm{sec}$, and the result of the test was the number of repetitions; (iii) general flexibility was measured by the Chair Sit and Reach Test (CSRT), and it was measured in distance $(\mathrm{cm})$. If distance indicates the touch of fingertips and the toes, it means $0 \mathrm{~cm}$, if it does not touch, it means a negative score, if it overlaps, it means a positive score; (iv) aerobic fitness was measured by the 6-Minute Walk Test (6MWT), and it was measured in distance $(\mathrm{m})$, indicating endurance.

In the BBS, 14 motor tasks were evaluated: sitting to standing, standing unsupported, sitting with back unsupported, standing to sitting, transfers (the transition from chair to chair), standing with eyes closed, standing with feet together, reaching forward with outstretched arm, retrieving object from floor, turning to look behind, turning 360 degrees, placing alternate foot on step, standing with one leg in front, and standing on one leg. The observers rated their evaluation selecting the appropriate position on a five-point scale. Position 1 marked the lowest, and position 5 the highest level of the skill.

Attention process was assessed by a standardized $\mathrm{d} 2$ test, ${ }^{[26,27]}$ and three variables were tested: (i) the ability to identify the number of specific symbols $(\mathrm{d} 2 \mathrm{SN})$, (ii) the number of errors during perception (d2EN), and (iii) the measure of concentration (d2MC).

All test procedures were performed under standardized conditions. During the measurements, the respondents were in sports equipment and of stable health status (without acute health changes).

\section{Statistical analysis}

The study power and sample size calculation were performed using the $G^{\star}$ Power version 3.1.9.7 software (Heinrich-Heine Universität Düsseldorf, Düsseldorf, Germany). ${ }^{[19]}$ Using the Cohen's recommended effect size index $(f[V]=0.6)$, a error probability 0.05 and power analysis (1- $\beta$ ) 0.8 , the following tests were used: (i) test family - F-test; (ii) statistical test analysis of variance (ANOVA), repeated measures 
within-between interaction; and (iii) type of power analysis - a priori: Compute required sample size given $\alpha$, power and effect size. The effect size decided upon was 0.6 , as it indicates surely a middle impact of independent variables, ${ }^{[20]}$ thus requiring the total sample size of 24 participants.

Statistical analysis was performed using the IBM SPSS version 21.0 software (IBM Corp., Armonk, NY, USA). Descriptive data were expressed in mean \pm standard deviation (SD), median (min-max) or number and frequency, where applicable. To test the significance of differences between the results of groups on the pre-test (groups' homogenization), independent samples t-test was applied. To analyze the effects of the experimental treatment, repeated measures ANOVA that combined two subjects was used: the time and the specificity of groups, which is called the mixed between-within subjects ANOVA. ${ }^{[28]}$ The Box's tests of equality of covariance matrices and Levene's test of equality of error variances were used to confirm whether the assumptions were fulfilled for all the variables. A $p$ value of $<0.05$ was considered statistically significant.

\section{RESULTS}

Descriptive data of the study groups are shown in Table 1. Statistically significant differences between the experimental and control group in pretest were not obtained for any of the eight variables: $\operatorname{CST}(\mathrm{t}=1.699 ; \mathrm{p}=0.103)$, BCT $(\mathrm{t}=0.967 ; \mathrm{p}=0.344)$, CSRT $(\mathrm{t}=1.487 ; \mathrm{p}=0.151), 6 \mathrm{MWT}(\mathrm{t}=1.830 ; \mathrm{p}=0.080)$, BBS $(\mathrm{t}=1.443 ; \mathrm{p}=0.163), \mathrm{d} 2 \mathrm{SN}(\mathrm{t}=-0.710 ; \mathrm{p}=0.485)$, $\mathrm{d} 2 \mathrm{EN}(\mathrm{t}=-0.446 ; \mathrm{p}=0.660)$ and $\mathrm{d} 2 \mathrm{MC}(\mathrm{t}=-0.546$; $\mathrm{p}=0.591)$.

During the eight-week experimental period, a statistically significant improvement was observed in five of the eight variables. The patients increased lower extremity strength, upper limb strength, balance and concentration, and reduced the number

\begin{tabular}{|lccccc|}
\hline \multicolumn{7}{|c|}{ TABLE 1 } \\
Descriptive data of the study participants & \\
\hline Patients (groups) & Number & Sex & Mean age & Category of TBI & Duration of treatment \\
\hline Experimental & 13 & Male & 40.62 & Moderate/severe & 2 years \\
Control & 12 & Male & 41.66 & Moderate/severe & 2 years \\
Total & 25 & Male & 41.12 & Moderate/severe & 2 years \\
\hline * The duration of the rehabilitation treatment before the beginning of the experiment. & \\
\hline
\end{tabular}

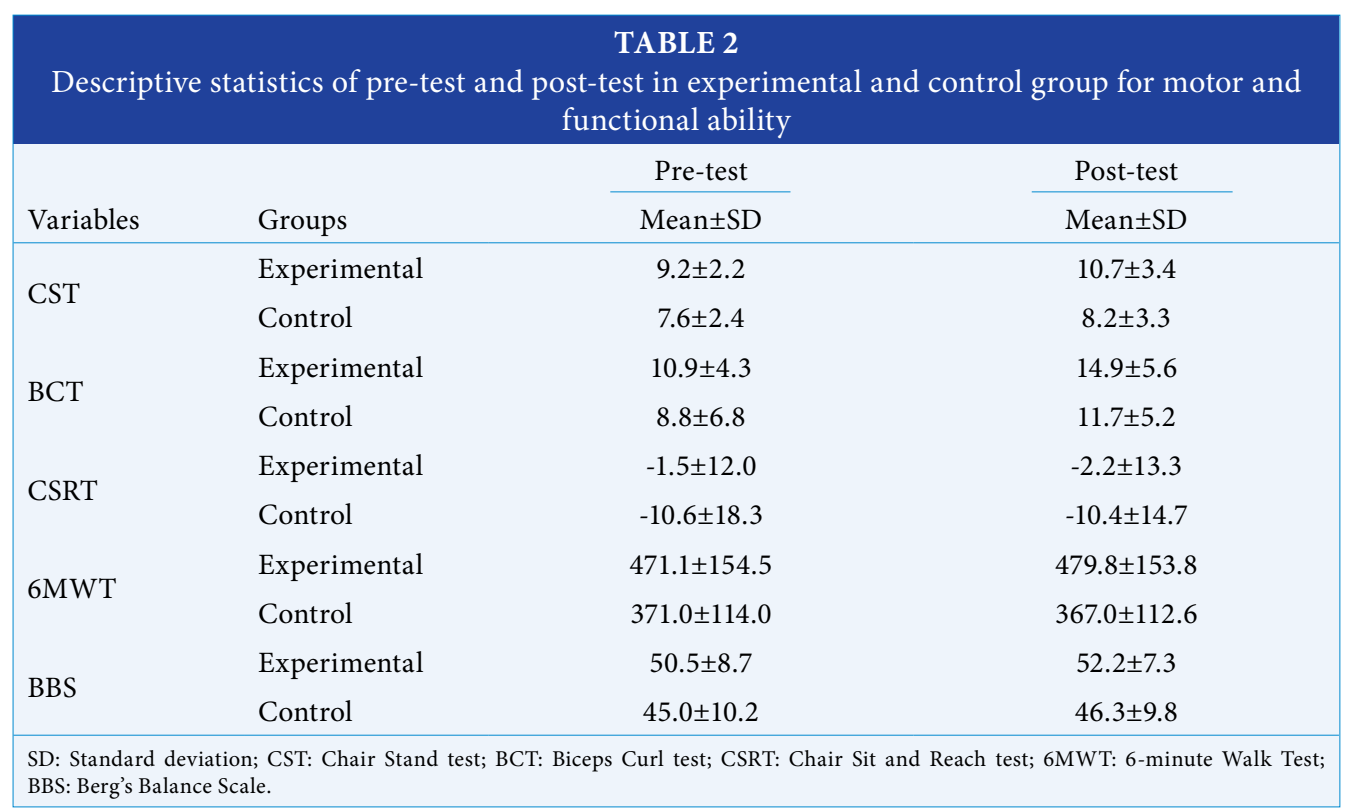




\begin{tabular}{|c|c|c|c|c|c|}
\hline \multicolumn{6}{|c|}{$\begin{array}{c}\text { TABLE } 3 \\
\text { Statistics of mixed between-within subjects ANO }\end{array}$} \\
\hline Variable/impact & Wilks' lambda & $\mathrm{F}$ & $p$ & Partial eta squared & Achieved power \\
\hline \multicolumn{6}{|l|}{ CST } \\
\hline Factor interaction & 0.939 & 1.485 & 0.235 & 0.061 & 0.215 \\
\hline Treatment impact & 0.758 & 7.330 & 0.013 & 0.242 & 0.737 \\
\hline Group difference & - & 3.573 & 0.071 & 0.134 & 0.441 \\
\hline \multicolumn{6}{|l|}{ BCT } \\
\hline Factor interaction & 0.983 & 0.408 & 0.529 & 0.017 & 0.094 \\
\hline Treatment impact & 0.580 & 16.628 & 0.000 & 0.420 & 0.974 \\
\hline Group difference & - & 1.774 & 0.196 & 0.072 & 0.248 \\
\hline \multicolumn{6}{|l|}{ CSRT } \\
\hline Factor interaction & 0.992 & 0.182 & 0.674 & 0.008 & 0.069 \\
\hline Treatment impact & 0.997 & 0.075 & 0.786 & 0.003 & 0.058 \\
\hline Group difference & - & 2.251 & 0.147 & 0.089 & 0.301 \\
\hline \multicolumn{6}{|l|}{$6 \mathrm{MWT}$} \\
\hline Factor interaction & 0.929 & 1.766 & 0.197 & 0.071 & 0.247 \\
\hline Treatment impact & 0.990 & 0.241 & 0.628 & 0.010 & 0.076 \\
\hline Group difference & - & 3.842 & 0.062 & 0.143 & 0.467 \\
\hline \multicolumn{6}{|l|}{ BBS } \\
\hline Factor interaction & 0.995 & 0.110 & 0.743 & 0.005 & 0.062 \\
\hline Treatment impact & 0.746 & 7.847 & 0.010 & 0.254 & 0.765 \\
\hline Group difference & - & 2.490 & 0.128 & 0.098 & 0.327 \\
\hline
\end{tabular}

\begin{tabular}{|c|c|c|c|}
\hline \multicolumn{4}{|c|}{$\begin{array}{c}\text { TABLE } 4 \\
\text { Descriptive statistics of pre-test and post-test in experimental and control group for the attentio } \\
\text { process }\end{array}$} \\
\hline \multirow[b]{2}{*}{ Variables } & \multirow[b]{2}{*}{ Groups } & Pre-test & Post-test \\
\hline & & Mean \pm SD & Mean \pm SD \\
\hline \multirow{2}{*}{$\mathrm{d} 2 \mathrm{SN}$} & Experimental & $204.5 \pm 103.0$ & $238.5 \pm 91.7$ \\
\hline & Control & $240.3 \pm 147.3$ & $223.8 \pm 117.3$ \\
\hline \multirow{2}{*}{$\mathrm{d} 2 \mathrm{EN}$} & Experimental & $30.3 \pm 28.2$ & $13.8 \pm 14.6$ \\
\hline & Control & $38.3 \pm 57.9$ & $20.8 \pm 26.9$ \\
\hline \multirow{2}{*}{$\mathrm{d} 2 \mathrm{MC}$} & Experimental & $57.2 \pm 35.7$ & $85.7 \pm 36.7$ \\
\hline & Control & $65.0 \pm 36.2$ & $75.3 \pm 37.4$ \\
\hline
\end{tabular}

of errors in the $\mathrm{d} 2$ test under the influence of adapted physical exercise. A significant effect of treatment was absent in the variables of general flexibility, aerobic fitness, and number of specific symbols perception (Tables 2 and 3). The absence of statistically significant changes in these three variables can be explained by a relatively short experimental period.
The post-test scores were better than the pre-test scores for all eight variables (Tables 4 and 5), indicating that adapted physical exercise caused positive changes in motor abilities and attention processes in patients with TBI. A higher improvement of all abilities was recorded in the experimental group, but the differences were not statistically significant $(\mathrm{p}>0.05)$. 


\begin{tabular}{|c|c|c|c|c|c|}
\hline \multicolumn{6}{|c|}{$\begin{array}{c}\text { TABLE } 5 \\
\text { in subjects }\end{array}$} \\
\hline Variable/impact & Wilks' lambda & $\mathrm{F}$ & $p$ & Partial eta squared & Achieved power \\
\hline \multicolumn{6}{|l|}{$\mathrm{d} 2 \mathrm{SN}$} \\
\hline Factor interaction & 0.812 & 5.318 & 0.030 & 0.188 & 0.598 \\
\hline Treatment impact & 0.973 & 0.639 & 0.432 & 0.027 & 0.119 \\
\hline Group difference & - & 0.055 & 0.816 & 0.002 & 0.056 \\
\hline \multicolumn{6}{|l|}{$\mathrm{d} 2 \mathrm{EN}$} \\
\hline Factor interaction & 1.000 & 0.010 & 0.921 & 0.000 & 0.051 \\
\hline Treatment impact & 0.684 & 10.616 & 0.003 & 0.316 & 0.877 \\
\hline Group difference & - & 0.329 & 0.572 & 0.014 & 0.085 \\
\hline \multicolumn{6}{|l|}{$\mathrm{d} 2 \mathrm{MC}$} \\
\hline Factor interaction & 0.771 & 6.836 & 0.015 & 0.229 & 0.707 \\
\hline Treatment impact & 0.425 & 31.168 & 0.001 & 0.575 & 1.000 \\
\hline Group difference & - & 0.008 & 0.930 & 0.000 & 0.051 \\
\hline
\end{tabular}

\section{DISCUSSION}

In patients with TBI, the most commonly impaired physical abilities are movement coordination, balance, muscle strength, and aerobic ability. All these, combined with insufficient attention and inadequate emotional regulation, result in impairment of overall psychophysical and working ability. Adapted endurance exercises (aerobic exercises) result in significant adaptation of the cardiovascular system in terms of cardiac (improvement of arterial diameter) and muscular function characterized by increased numbers of capillaries. A large number of studies have supported these adaptive processes that affect the improvement of aerobic power and endurance and, usually affect the improvement of cardiovascular health in sedentary individuals. ${ }^{[9,29-31]}$ In a sample of 10 patients with TBI, Chin et al. ${ }^{[10]}$ demonstrated that intense aerobic exercise three times a week for $30 \mathrm{~min}$ significantly increased aerobic ability and reduced the subjective feeling of exercise exertion. The results of our study did not show a significant improvement in aerobic fitness, which is probably due to a relatively short exercise period or an insufficiently strong training stimulus.

In regard to strength testing (upper and lower extremities), a significant improvement was observed in this study, which is consistent with the findings of Peters. ${ }^{[32]}$ At the final measurement, higher values were found in the experimental group, compared to the control group. However, the results indicated that a statistically significant increase occurred in both groups and, therefore, the improvement achieved cannot be attributed with certainty to the effects of the experimental program. The exercise compliance (frequency, attendance) is probably a more important factor in rehabilitation than the volume and intensity of activity. In this study, both groups exercised every weekday, and the experimental group had additional activities.

Although not statistically significant, the higher average values in the experimental group can be explained by the greater motivation of the participants. All patients were the users of the Center for People with Traumatic Brain Injury and were already enrolled in the rehabilitation program before the experiment. Additional treatment was only applied in the experimental group and probably contributed to an increase in exercise motivation. Still, a short-term intervention with adapted exercise program proved successful in terms of strength improvement.

Normal functioning of the musculoskeletal system is necessary to maintain balance. In addition to reducing muscle strength and reduced flexibility as well as movement volume, TBI patients also reduce the ability to respond to changes in movement that can lead to a fall. The experimental program in this study did not produce a significant increase in flexibility, which may be explained by a relatively short treatment duration or poor training stimuli.

After the experimental program, the respondents of both groups scored significantly more points on the BBS, and it can be speculated that the intervention 
had a significant impact on the balance. In the study of Peters ${ }^{[32]}$ that lasted for four weeks with five training sessions per week, the participants showed an improvement in walking speed, mobility and balance, as assessed by the BBS. Clinically significant changes in balance after applying exercises, identified on the BBS in patients with TBI, are related to the decrease in the risk of falling. ${ }^{[33]}$

The results of this study indicate a significant effect of adapted physical exercise on improving attention. The speed criterion, that is, the total number of all crossed out characters in a given unit of time, did not improve significantly. However, there was a significant improvement in the processing accuracy that was obtained by summing up all the errors made. Likewise, a positive result was obtained in the concentration measurement determined by subtracting the number of errors from the number of correctly crossed characters. This is of utmost importance, as the $\mathrm{d} 2$ test requires the individual to concentrate on external visual stimuli. Under the term concentration, it refers to an efficient, continuous, and focused choice of stimuli, that is, an individual's ability to selectively choose particular symbols, while excluding irrelevant stimuli in continuous, quickly and correctly analyzed tasks and in accordance with internal and/or external stimuli. The results of this study suggest that adapted physical exercise can improve social or psychological outcomes, which are important aspects of quality of life after TBI.

Nonetheless, there are some limitations to this study, which could be related to the small number of subjects in the sample, insufficient anamnestic data on the level of physical ability before traumatic brain injury.

In conclusion, the eight-week experimental treatment produced a statistically significant improvement of strength, balance, attention and concentration in patients with TBI. These results indicated a significant improvement in both groups (in the control who had only the regular rehabilitation treatment and the experimental who had additional sessions of adapted physical exercise). Based on these findings, compliance (continuity) is a more important factor in rehabilitation than the volume and intensity of activity. This study confirms the findings of previous studies, proving that daily exercise plays an important role in improving the working ability of patients with TBI.

\section{Acknowledgements}

The authors give their special thanks to participants who agreed to participate in this study and contribute to the project implementation "European sports network for rehabilitation of persons with disabilities - ReSport", co-founded by the Erasmus+ Program of the European Union. The participants in this study made it possible to better understand the link between physical activity and physical/work ability in patients with TBI.

\section{Declaration of conflicting interests}

The authors declared no conflicts of interest with respect to the authorship and/or publication of this article.

Funding

The study was financially supported by the Erasmus+ project of the European Union (No: 2016-3634/001-001).

\section{REFERENCES}

1. Grabljevec K. Clinical guidelines for adult rehabilitation after accidental injury. Ljubljana, University Rehabilitation Institute of the Republic of Slovenia. Soča 2014;1:53-68

2. Bakran Ž, Schnurrer-Luke-Vrbanić T, Kadojić M. Guidelines in the rehabilitation of patients with traumatic brain injury. PM\&R 2015;27:270-301

3. Williams G, Ada L, Hassett L, Morris ME, Clark R, Bryant $\mathrm{AL}$, et al. Ballistic strength training compared with usual care for improving mobility following traumatic brain injury: protocol for a randomised, controlled trial. J Physiother 2016;62:164.

4. Antal Z, Čeh M, Danesh O. Handbook for working with persons with acquired brain injury, Ljubljana, Center for People with Acquired Brain Injury Zarja; 2011.

5. Gennarelli TA, Graham DI. Neuropathology. In: Silver JM, McAllister TW, editors. Textbook of traumatic brain injury. Washington DC: American Psychiatric Publishing; 2005. p. 27-50.

6. Saatman KE, Duhaime AC, Bullock R, Maas AI, Valadka A, Manley GT; Workshop Scientific Team and Advisory Panel Members. Classification of traumatic brain injury for targeted therapies. J Neurotrauma 2008;25:719-38.

7. O'Neil ME, Carlson K, Storzbach D, Brenner L, Freeman M, Quiñones A, et al. Complications of mild traumatic brain injury in veterans and military personnel: A systematic review [Internet]. Washington (DC): Department of Veterans Affairs (US); 2013.

8. Kozlowski DA, Leasure JL, Schallert T. The control of movement following traumatic brain injury. Compr Physiol 2013;3:121-39.

9. Mossberg KA, Amonette WE, Masel BE. Endurance training and cardiorespiratory conditioning after traumatic brain injury. J Head Trauma Rehabil 2010;25:173-83.

10. Chin LM, Chan L, Woolstenhulme JG, Christensen EJ, Shenouda CN, Keyser RE. Improved cardiorespiratory fitness with aerobic exercise training in individuals with traumatic brain injury. J Head Trauma Rehabil 2015;30:382-90.

11. Williams GP, Morris ME. Tests of static balance do not predict mobility performance following traumatic brain injury. Physiother Can 2011;63:58-64. 
12. Williams GP, Schache AG, Morris ME. Mobility after traumatic brain injury: Relationships with ankle joint power generation and motor skill level. J Head Trauma Rehabil 2013;28:371-8.

13. Garber CE, Blissmer B, Deschenes MR, Franklin BA, Lamonte MJ, Lee IM, et al. Quantity and quality of exercise for developing and maintaining cardiorespiratory, musculoskeletal, and neuromotor fitness in apparently healthy adults: Guidance for prescribing exercise. Med Sci Sports Exerc 2011;43:1334-59.

14. Billinger SA, Arena R, Bernhardt J, Eng JJ, Franklin $\mathrm{BA}$, Johnson CM, et al. Physical activity and exercise recommendations for stroke survivors: A statement for healthcare professionals from the American Heart Association/American Stroke Association. Stroke 2014;45:2532-53.

15. Brogårdh C, Lexell J. Effects of cardiorespiratory fitness and muscle-resistance training after stroke. PMR 2012;4:901-7.

16. Curran CA, Ponsford JL, Crowe S. Coping strategies and emotional outcome following traumatic brain injury: A comparison with orthopedic patients. J Head Trauma Rehabil 2000;15:1256-74.

17. Basford JR, Chou LS, Kaufman KR, Brey RH, Walker A, Malec JF, et al. An assessment of gait and balance deficits after traumatic brain injury. Arch Phys Med Rehabil 2003;84:343-9.

18. Chin LM, Chan L, Woolstenhulme JG, Christensen EJ, Shenouda CN, Keyser RE. Improved cardiorespiratory fitness with aerobic exercise training in individuals with traumatic brain injury. J Head Trauma Rehabil 2015;30:382-90.

19. Faul F, Erdfelder E, Lang AG, Buchner A. G*Power 3: A flexible statistical power analysis program for the social, behavioral, and biomedical sciences. Behav Res Methods 2007;39:175-91.

20. Cohen JW. Statistical power analysis for the behavioral sciences. 2nd ed. New York: Lawrence Erlbaum Associates; 1988.

21. Dennison PE. Brain Gym ${ }^{\circledast}$ and me: Reclaiming the pleasure of learning. Ventura, CA: Edu-Kinesthetics; 2006.
22. Ownsworth T, Haslam C. Impact of rehabilitation on selfconcept following traumatic brain injury: An exploratory systematic review of intervention methodology and efficacy. Neuropsychol Rehabil 2016;26:1-35.

23. Langhammer B, Stanghelle JK. The senior fitness test. J Physiother 2015;61:163.

24. Langhammer B, Stanghelle JK. Senior fitness test; A useful tool to measure physical fitness in persons with acquired brain injury. Brain Inj 2019;33:183-8.

25. Newstead AH, Hinman MR, Tomberlin JA. Reliability of the berg balance scale and balance master limits of stability tests for individuals with brain injury. J Neurol Phys Ther 2005;29:18-23.

26. Bates ME, Lemay EP Jr. The d 2 Test of attention: Construct validity and extensions in scoring techniques. J Int Neuropsychol Soc 2004;10:392-400.

27. Schönberger M, Humle F, Zeeman P, Teasdale TW. Patient compliance in brain injury rehabilitation in relation to awareness and cognitive and physical improvement. Neuropsychol Rehabil 2006;16:561-78.

28. Tabachnick BG, Fidell LS. Using multivariate statistics. Boston: Pearson Education; 2007.

29. Hellsten Y, Nyberg M. Cardiovascular adaptations to exercise training. Compr Physiol 2015;6:1-32.

30. Irwin K, Ede A, Harsh B. Physical activity and traumatic brain injury. Strength Cond J 2011;33:43-7.

31. Schwandt M, Harris JE, Thomas S, Keightley M, Snaiderman A, Colantonio A. Feasibility and effect of aerobic exercise for lowering depressive symptoms among individuals with traumatic brain injury: A pilot study. J Head Trauma Rehabil 2012;27:99-103.

32. Peters DM, Jain S, Liuzzo DM, Middleton A, Greene J, Blanck E, et al. Individuals with chronic traumatic brain injury improve walking speed and mobility with intensive mobility training. Arch Phys Med Rehabil 2014;95:1454-60.

33. Alghwiri AA, Whitney SL. Balance and falls. In: Guccione A, Wong R, Avers D, editors. Geriatr Phys Ther. 3rd ed. St. Louis: Elsevier Inc.; 2012. p. 331-53. 